Eadie, J. M., Mann, S. O. \& Oxford, A. E. (1956). J. gen. Microbiol. 14, 122133

\title{
A Survey of Physically Active Organic Infusoricidal Compounds and their Soluble Derivatives with Special Reference to their Action on the Rumen Microbial System
}

\author{
By J. MARGARET EADIE, S. O. MANN AND A. E. OXFORD \\ Rowett Research Institute, Bucksburn, Aberdeenshire
}

\begin{abstract}
SUMMARY: Many sparingly water-soluble neutral substances, including several indole derivatives, will quickly kill and often disintegrate washed living rumen ciliates at $35-39^{\circ}$, when acting at or near the saturation point $(0 \cdot 002-0 \cdot 1 \mathrm{M})$ in a phosphate + acetate buffer at $\mathrm{pH} 7$. The toxic compounds are mostly readily soluble in light petroleum. Organisms of the genera Isotricha, Dasytricha and Ophryoscolex, in particular, exhibit characteristic modes of disintegration when acted upon by such substances. Prominent among these are the terpene alcohols menthol, borneol and isoborneol, and their more soluble glucosides (both $\alpha$ - and $\beta$-) and their acid succinates. Menthoxyacetic acid is also similarly toxic. On the other hand, menthol and borneol $\beta$-glucuronides are not toxic to the rumen ciliates unless added to rumen contents containing bacteria also. Unlike menthol, borneol, in nearly saturated solution, is not particularly toxic to the rumen bacterial species Streptococcus bovis and Sarcina bakeri and quite high concentrations $(0 \cdot 1-0 \cdot 4 \%)$ of the terpenoid succinates and glucosides are required for even partial inhibition of the growth of true rumen saccharolytic bacteria under otherwise favourable conditions. The population of lipolytic (esterase producing) bacteria in rumen contents from a hay and dried grassfed sheep was of the order of 500,000/g. rumen contents. Bacillus licheniformis was the chief anaerobic lipolytic species isolated.
\end{abstract}

Although much is now known about carbohydrate fermentations by rumen ciliate protozoa (see Hungate, 1955, for summary), very little success has attended efforts to cultivate individual species in chemically defined media. Consequently, their nitrogen metabolism is still a closed book, and we do not know whether the conversion of part of the fodder organic-N into protozoan protein of higher nutritional value, which undoubtedly takes place in the rumen (see McNaught, Owen, Henry \& Kon, 1954), is accompanied by an appreciable loss of fodder protein nitrogen as ammonia, or by destruction of B-vitamins synthesized by rumen bacteria. To obtain evidence on these points it might help greatly to be able to maintain individual protozoan species in the rumen of living sheep. The simplest way to do this might be to defaunate a sheep under conditions bringing about the minimum of harm to the rumen bacteria and to the host and then to introduce the single ciliate species under investigation in the hope that it would multiply and maintain itself in the rumen. Something along these lines has already been attempted by Becker, Schulz \& Emmerson (1930) with goats, but they used a relatively drastic method of defaunation, viz. long-continued starvation followed by dosing with copper sulphate solution at definitely bactericidal concentrations. New infusoricidal agents, which have little toxic action on the host or its rumen bacteria, 
seem to be required for the end in view. This paper explores the possibilities of physically active organic substances (cf. Ferguson, 1939) in this respect, by means of in vitro methods.

Eadie \& Oxford (1954) showed that the sparingly soluble neutral substances indole and skatole, which might even arise naturally by bacterial action on tryptophan in the rumen, were very toxic to rumen ciliates when acting at or near the aqueous saturation point. We have now shown that this is a general property of sparingly water-soluble but readily hydrocarbon-soluble, neutral substances, and have particularly directed our attention to the terpene alcohols since these can be made more water-soluble by linking to residues, such as glucose, glucuronic or succinic acids which are known to be attacked by rumen bacteria. If these compounds are so attacked in the rumen itself, a saturated solution of the terpene alcohol might quickly be produced throughout its contents following one massive dose of the solubilized form of the alcohol. The advantages of borneol and isoborneol in this respect are increased by the ease with which mammals can excrete such compounds in the urine, almost exclusively as $\beta$-glucuronides (see Williams, 1947). Rumen bacteria are known to secrete $\alpha$-glucosidase (e.g. Streptococcus bovis ferments maltose), $\beta$-glucosidase (Conchie, 1954), $\beta$-glucuronidase (Karunairatnam \& Levvy, 1951), and an enzyme system fermenting succinate (see Sijpesteijn \& Elsden, 1952), although no one seems previously to have studied rumen bacterial esterase such as might hydrolyse the alkyl esters of succinic acid to the free alcohol and acid. We have therefore completed our study by computing and isolating the chief lipase (esterase)-containing bacteria, in the rumen of a hay and dried grass-fed sheep, which are able to act anaerobically.

\section{METHODS}

\section{Compounds tested for infusoricidal activity}

Unless otherwise stated, the compounds listed below were good-quality laboratory reagents purchased from British Drug Houses Ltd. or L. Light and Co. Ltd. Other compounds were specially prepared or given by the persons mentioned in the acknowledgements at the end of this paper.

(a) Hydrocarbons: toluene (Analar, redistilled); naphthalene.

(b) Non-nitrogenous alcohols: borneol; dulcitol; geraniol; isoborneol; menthol; 1-phenylethanol (Klages \& Allendorff; 1898); 2-phenylethanol; stilboestrol; terpin hydrate; $\beta$-ionone (an odoriferous ketone) was also included for comparison.

(c) Non-nitrogenous ethers: anisole; cineole; menthoxyacetic acid (Organic Syntheses, 1955).

(d) Indole derivatives: di-indolylmethane; $\omega$-hydroxyskatole (Leete \& Marion, 1953); 1-methylindole (Potts \& Saxton, 1954); 7-methoxy-2-methylindole (see acknowledgements); 4-methoxy-1-methylindole; 5-methoxyindole; 5-methoxy-1-methylindole; 7-methoxy-1-methyl-indole; 7-methoxy-1:3-dimethylindole (see acknowledgements); 2-phenylindole; skatole (recrystallized from light petroleum); tryptophol (2-indolylethanol; Ehrlich, 1912). 
(e) Glucosides and glucuronides with sparingly soluble aglycones: menthol- $\beta$ glucoside (Fischer \& Raske, 1909); borneol- $\alpha$-glucoside, menthol- $\beta$-glucuronide (see acknowledgements). Borneol- $\beta$-glucuronide. This was prepared as follows: borneol ( $5 \mathrm{~g}$. in aqueous suspension) was administered directly through the cannula to the rumen of a fistulated hay-fed sheep, on six separate occasions more or less evenly spread over 3 days. During this period, its urine was collected, pooled, and from it was prepared the insoluble zinc salt of borneol- $\beta$ glucuronide as described by Quick (1927) for borneol-fed dog urine. Since the preparation of the free glucuronide from the zinc salt is said not to be quantitative, it was considered best, for the purposes of in vitro testing, to convert the crude zinc salt into the soluble potassium salt by grinding the dried material (3 g.) with a solution of $\mathrm{K}_{2} \mathrm{HPO}_{4}(2 \cdot 1 \mathrm{~g}$.) in distilled water (75 ml.). After standing for $1 \mathrm{hr}$. with occasional stirring, the insoluble zinc phosphate was removed by centrifuging and the supernatant finally cleared by filtration to yield an approximately $1 \cdot 3 \%(\mathrm{w} / \mathrm{v})$ solution of borneol- $\beta$-glucuronide at $\mathrm{pH} 7$.

(f) Monoalkyl succinates yielding sparingly soluble alcohols on hydrolysis. Monomenthyl, monobornyl, and monoisobornyl succinates were prepared by heating the appropriate terpene alcohol with excess of succinic anhydride at $150^{\circ}$ (not higher because of possible dehydration of the alcohol to yield hydrocarbons) for $6 \mathrm{hr}$. (Beckmann, 1909). The melt was cooled, triturated with cold light petroleum (b.p. $40-60^{\circ}$; in which succinic anhydride is insoluble) filtered and the filtrate decolorized with a little charcoal, and finally evaporated to dryness in vacuo $\left(20 \mathrm{~mm}\right.$.) at $50^{\circ}$. Crude monomenthyl succinate so prepared was a solid m.p. $50^{\circ}$ (lit. $59^{\circ}$ ) and was purified by recrystallization from aqueous ethanol. The other two acid succinates, although of approximately correct equivalent weights, were pale yellow oils. Since the starting products were not optically pure it was not considered worth while to attempt to purify these esters. All three monoalkyl succinates were completely soluble in cold sodium carbonate solution.

(g) Compounds acting entirely, or in part, by chemical toxicity. For comparative purposes, the very sparingly soluble phenolic substance eugenol and the organic arsenical, $m$-amino- $p$-hydroxyphenyl-arsine hydrochloride (Mapharside; Parke, Davis and Co.) were also tested. The first-named compound no doubt can partly act by a physical mechanism also. It was included because it is the aglycone of the naturally occurring plant $\beta$-glucoside gein.

Preparation of washed suspensions of living rumen ciliate protozoa for testing the infusoricidal compounds. The method of Eadie \& Oxford (1955) for obtaining washed suspensions of undamaged motile ciliates was used, preferably with addition of galactose rather than glucose. Some living oligotrich ciliates were always present in these suspensions. The same two fistulated hay-, or hay and dried grass-fed sheep were employed as in the previous study, viz. nos. 1004 and 8060. The latter animal was especially useful for providing oligotrichs including Ophryoscolex spp. The buffer solution used for removal of extraneous bacteria, by washing by decantation, and for subsequent maintenance of the protozoa in the living state, was again the simplest possible, viz. $(\%, w / v)$ 
$\mathrm{NaCl}, 0.5 ;$ anhydrous sodium acetate, $0 \cdot 13 ; \mathrm{KH}_{2} \mathrm{PO}_{4}, 0.03 ; \mathrm{K}_{2} \mathrm{HPO}_{4}, 0 \cdot 10$; $\mathrm{MgSO}_{4}, 7_{\mathrm{H}_{2}} \mathrm{O}, \mathbf{0} \cdot 01 ; \mathrm{pH} \mathrm{7 \cdot 2}$. During the first few hours in this buffer at $39^{\circ}$, the oligotrichs, as well as the holotrichs, remained alive, i.e. with visible ciliary motion even when the organism as a whole remained stationary; so that a toxic effect of an added substance on all the rumen genera could be demonstrated when the test was carried out immediately after preparation of the washed protozoan suspension. When the washed protozoan deposit at the bottom of a $50 \mathrm{ml}$. boiling tube filled with buffer was allowed to stand overnight at $39^{\circ}$, no especial precautions being taken to exclude air or to maintain highly reducing conditions, only the holotrichs and Ophryoscolex survived. Such suspensions could therefore be used for confirming results obtained on the previous day, with respect to three rumen genera only. Small preparations of living Isotricha free from Dasytricha, and of Dasytricha free from Isotricha, were obtained by the method of Gutierrez (1955).

Methods for testing infusoricidal activity against washed suspensions of ciliates. The solubility of a neutral compound under test in the buffer at about $45^{\circ}$ was first roughly determined by trial and error. Slightly more of the compound than necessary to give $10 \mathrm{ml}$. saturated solution at this temperature was then weighed into a $\mathbf{5} \times \mathbf{0 . 5}$ in. (internal diam.) test-tube. Buffer solution (10 ml.) was added to fill the test-tube about two-thirds full. The tube was placed in a water-bath at $45^{\circ}$ and its contents slowly stirred by hand, by means of a thin glass rod, for at least $15 \mathrm{~min}$. until no more substance appeared to dissolve. When an appreciable amount of the substance appeared to remain undissolved, the liquid was filtered through a very small fluted Whatman no. 1 paper into another test-tube. Skatole $(4 \mathrm{mg} . / 10 \mathrm{ml}$.) was always used in the positive control tube and a no-substrate control (i.e. buffer only) was also always included. The water-bath (usually a $250 \mathrm{ml}$. beaker) containing the test-tubes immersed up to the level of the liquid inside them, was then placed in a $39^{\circ}$ incubator, and when the temperature of the water in the bath had fallen to $38^{\circ}, 0 \cdot 1 \mathrm{ml}$. of clean washed ciliate suspension was added to each tube. This was best achieved in the following way: the washed stock ciliate suspension in buffer at the bottom of a $50 \mathrm{ml}$. boiling tube, and a number of graduated 1 and $2 \mathrm{ml}$. pipettes, slides and coverslips having been placed in the incubator well beforehand, a pipette-full of the bottom protozoan layer was quickly sucked up when required for inocula and $\mathbf{0 . 1 5} \mathrm{ml}$. immediately run out into each of the test-tubes in the water-bath. Great expedition was here required, otherwise the protozoa would settle under gravity, even in the pipette itself. Each inoculated tube was rotated by hand in such a way that the protozoa were evenly suspended without the introduction of air bubbles into the liquid. In some instances, dilutions in buffer were made from a saturated solution and inoculated likewise in order to determine whether a nearly saturated solution was needed for the full toxic effect. The appearance of the protozoa was noted after $30,60,120$, and $180 \mathrm{~min}$. by the following procedure. The tube was first shaken as before to indicate whether a permanent turbidity (due to release of storage grains and inclusions from disrupted organisms) was produced. Five min. later, about $0.02 \mathrm{ml}$. of the bottom deposit was quickly transferred to 
a slide, the cover-slip added and the preparation quickly transferred to a not too cold microscope stage. The microscope itself could be advantageously kept in a $39^{\circ}$ incubator between periods of use.

A convenient source of illumination was northern daylight and the $\frac{2}{3}$-inch objective would reveal sufficient detail for the purpose. Besides obviously disrupted and obviously motile ciliates, those motionless as a whole were carefully examined to discover whether all ciliary motion had entirely ceased. The temperature of the water-bath in the incubator was at no time allowed to fall below $35^{\circ}$. When necessary it was from time to time taken out and warmed to $39^{\circ}$ on a wire gauze over a small bunsen burner.

When the compound to be tested was acidic, an endeavour was made to dissolve it directly in the buffer. Provided the $\mathrm{pH}$ value did not fall below 6.5 , the test could then be carried out. Otherwise, appropriate volumes of a concentrated solution of the acid in the correct amount of $\mathrm{NaOH}$ solution for neutralization were added to at least $10 \mathrm{vol}$. of the buffer to give the concentrations of toxic agent required.

Methods for testing infusoricidal activity against the ciliates in the rumen microbial system as a whole containing bacteria also. Strained rumen liquor without added sugar $(50 \mathrm{ml}$.) was placed in each of two pear-shaped $100 \mathrm{ml}$. separating funnels kept in the incubator. To one was added the toxic agent in neutral buffer solution, the total volume in the funnel being made up to $75 \mathrm{ml}$., when necessary, with buffer. To the other was added buffer solution only $(25 \mathrm{ml}$.). The contents of the funnels were mixed after $0,15,30 \mathrm{~min}$. and so on, as necessary. Five min. later a little of the bottom deposit in each was withdrawn as before and examined under the microscope. When complete mortality of the ciliates seemed to have occurred in the funnel containing toxic agent, $1 \mathrm{ml}$. of washed living ciliate suspension was added to each funnel and the incubation continued as before, with frequent microscopic examination of the bottom deposits.

\section{Bactericidal effect of infusoricidal compounds upon authentic rumen bacteria}

Isolation of Streptococcus bovis after action of the compound upon the whole rumen microbial system. Streptococcus bovis, the typical rumen starchfermenting streptococcus (MacPherson, 1953), is not usually found as an air or fodder-borne contaminant (Mann, Masson \& Oxford, 1954). Its isolation from the rumen microbial system after death of all rumen ciliates is therefore at least an indication that not all true rumen bacteria have been killed by the infusoricidal agent. This isolation was attempted by transferring loopfuls of well-shaken funnel contents (see previous section) into tubes of glucose + Lemco broth, and after $18 \mathrm{hr}$. of incubation at $38^{\circ}$, when usually a dense turbidity had developed and the $\mathrm{pH}$ value had fallen to $4-5$, the culture was examined for Gram-positive cocci existing in pairs and chains. When these were observed, streaks were made on to starch nutrient agar plates. After overnight incubation the plates were flooded with dilute Lugol's iodine in order to detect clear zones of starch hydrolysis around any tiny typically strepto- 
coccal colonies which might have developed. These had to be searched for, since the preponderant growth was always of Gram-positive rods.

Inhibitory effect of soluble infusoricidal agents upon the anaerobic development, in nutrient agar, of rumen bacteria taken directly from the rumen. This was attempted only with the glucosides and acid succinates of the terpene alcohols. An approximately $2 \%$ (when feasible, otherwise an almost saturated) solution of the compound was adjusted to $\mathrm{pH} 7-8$ and sterilized by filtration through a Berkefeld candle (type $\mathrm{kN}$; Baird \& Tatlock Ltd.,) and the filtrate incorporated into a number of plates of nutrient agar, prepared as described by Huhtanen, Rogers \& Gall (1952) to give a range of concentrations from 0.5 to $0.01 \%$ in the final agar. The inoculum for each poured plate (including one containing no toxic agent) was $1 \mathrm{ml}$. of a $10^{-4}$ dilution of rumen contents freshly taken from sheep 8060. Colonies were counted after 4 days of anaerobic incubation at $38^{\circ}$.

Bactericidal action of menthol, borneol and 2-phenylethanol upon pure cultures of true rumen bacteria. Streptococcus bovis and Sarcina bakeri (Mann et al. 1954) were the test organisms. Saturated aqueous solutions of the compounds were sterilized by filtration through sintered glass (Jobling Pyrex; bacteriological grade 5/3), and added to triple-strength glucose nutrient broth to give a maximum final concentration of two-thirds saturation. All tubes were made up to the same volume with sterile distilled water and inoculated with a loopful of a young broth culture of the test organism. Tubes were examined after 2 days of incubation at $38^{\circ}$ and in order to confirm an apparent bactericidal effect subcultures were made from those which showed no turbidity. Further tests, with appropriate solvent and medium controls, were also made by adding sterile $11.2 \%(\mathrm{w} / \mathrm{v})$ ethanolic solutions of the compounds to glucose nutrient broth, up to a maximum of $1.3 \%(\mathrm{v} / \mathrm{v})$ ethanol in the final medium.

Isolation of lipase-producing rumen bacteria in pure culture. The assumption being made that bacteria capable of hydrolyzing tributyrin at $\mathrm{pH} \mathrm{6-7} \mathrm{might}$ also hydrolyse at this $\mathrm{pH}$ value the monoalkyl succinates used as potential infusoricidal agents, it became of interest to determine whether the rumen mixed culture really contained an appreciable population of such bacteria acting anaerobically. The Huhtanen, Rogers \& Gall (1952) technique previously employed (see above) was therefore modified by incorporation of $1.25 \%(\mathrm{v} / \mathrm{v})$ tributyrin (British Drug Houses Ltd.), sterilized separately in concentrated gelatin suspension (Eisenberg, 1939), into the nutrient agar to give a wellmarked turbidity. Serial dilutions of freshly withdrawn rumen contents were employed as inocula for poured plates as before. After 4 days of anaerobic incubation at $38^{\circ}$ the number of colonies in each plate surrounded by a definite zone of clearing was counted. Subcultures were made from such colonies to fresh tributyrin agar and if zones of clearing again appeared upon anaerobic incubation, the isolates were purified and attempts made to identify them by the standard procedures for the genus in question. 


\section{RESULTS}

Nature of the visible damage sustained by rumen ciliates due to physically-active compounds

As stated by Eadie \& Oxford (1954) the outer membranes (ectoplasmic zone) of the holotrichs, to which the cilia are attached, were broken or torn off, sometimes indeed apparently 'dissolved' away with liberation of storage and other granules from the endoplasm, which often streamed away from the wrecked organism. Ophryoscolex also exhibited a characteristically damaged appearance, resembling a thick half-snapped twig; and the relatively lengthy dorsal membranelle zone of cilia, which is clearly the chief region of mechanical weakness in the organism, was often completely ripped off, with consequent oozing out of the internal contents. The other oligotrichs (Diplodinium and related genera and Entodinium) have however a tough outer cuticle (Dogiel, 1927) which protects the ciliary zones. Consequently, they showed no obvious damage save the cessation of ciliary motion. By contrast, the chemically active Mapharside, although lethal at a low concentration $(0.005 \%)$ did not cause disintegration even at much higher concentrations, the holotrichs for example dying with their ectoplasmic zone intact and their cilia extended more or less rigidly. The dorsal membranelle zone of Ophryoscolex was also unaffected by Mapharside.

\section{Solubilities in water and infusoricidal action at and below saturation point of neutral compounds tested}

The literature contains few determinations of aqueous solubility of these compounds at $40^{\circ}$ or thereabouts. Table 1 lists our own rough solubility determinations and such information as we could find in the literature for 'room temperatures'. It also indicates whether or not the compound, in nearly saturated solution, is characteristically toxic. The following practically insoluble compounds, not included in Table 1, were not highly toxic: di-indolylmethane; 4- and 5-methoxy-1-methylindoles; 7-methoxy-1:3-dimethylindole; 2-phenylindole; $\omega$-hydroxyskatole was too rapidly decomposed by warm water to give reliable results by the method used. Of the compounds which are appreciably water-soluble and are listed in Table 1 as not particularly toxic, dulcitol is insoluble, terpin hydrate very sparingly soluble and anisole readily soluble in light petroleum (b.p. $40-60^{\circ}$ ) at the boiling point. All the toxic compounds, with saturation points at $0 \cdot 002-0 \cdot 1 \mathrm{M}$ are appreciably soluble in light petroleum with the exception of the glucosides, which are insoluble.

Irrespective of actual solubility at the saturation point, the toxicities of the purely physically-active compounds in Table 1 fell off quite rapidly with decreasing concentration, so that at concentrations less than half saturation no particular action on the ciliates was shown over long periods of time. Exceptions to this behaviour were provided by eugenol, 2-phenylethanol and the glucosides. These compounds were fully active at concentrations well below half saturation. Menthol- $\beta$-glucoside $(0 \cdot 2 \%)$ was equally toxic to Isotricha and Dasytricha both in mixed and in separate 'pure' suspensions. 
Action of the acidic glucuronides, succinates and menthoxyacetic acid on washed suspensions of rumen ciliates

The glucuronides were quite inert. Menthol- $\beta$-glucuronide, for example, even at a concentration of $0.025 \mathrm{M}$, in buffer to which enough $\mathrm{NaHCO}_{3}$ had been added to bring to $\mathrm{pH} \mathbf{7 \cdot 2}$, had no action on the holotrichs during several hours at $38^{\circ}$.

Table 1. Solubilities of sparingly soluble neutral compounds in water at temperatures up to $45^{\circ}$ and action on washed ciliates at or near saturation point at 35-39 ${ }^{\circ}$

\begin{tabular}{|c|c|c|}
\hline Compounds & $\begin{array}{l}\text { Solubility at } 45^{\circ} \text { unless } \\
\text { otherwise stated (mole/1.) }\end{array}$ & $\begin{array}{l}\text { Action on ciliates } \\
=\text { death and disintegration } \\
\quad+=\text { death only } \\
0=\text { not highly toxic) }\end{array}$ \\
\hline Anisole & 0.01 & $\mathbf{0}$ \\
\hline Borneol & $0.004,0.005\left(25^{\circ}\right)^{*}$ & ++ \\
\hline Borneol- $\alpha$-glucoside & 0.01 (or greater) & ++ \\
\hline iso-Borneol & 0.002 & ++ (if unfiltered) \\
\hline Cineole & $0.02,0.01\left(20^{\circ}\right)^{*}$ & ++ \\
\hline Dulcitol & $0 \cdot 2\left(16^{\circ}\right)^{*}$ & $0 \quad$ (no action in \\
\hline Eugenol & 0.006 & ++ \\
\hline Geraniol & 0.004 & ++ \\
\hline$\beta$-Ionone & 0.003 & ++ \\
\hline Menthol & $0.004,0.0025\left(20^{\circ}\right)^{*}$ & ++ \\
\hline Menthol- $\beta$-glucoside & 0.013 & ++ \\
\hline 1-Methylindole & $0 \cdot 003$ & ++ \\
\hline 5-Methoxyindole & 0.005 & + \\
\hline 7-Methoxy-1-methylindole & 0.005 & ++ \\
\hline 7-Methoxy-2-methylindole & 0.0025 & ++ \\
\hline Naphthalene & $0.0002\left(20^{\circ}\right)^{*} \dagger$ & $\begin{array}{ll}0 & \text { (but definite } \\
\text { deleterious } \\
\text { action on } \\
\text { holotrichs) }\end{array}$ \\
\hline 1-Phenylethanol & 0.02 & ++ \\
\hline 2-Phenylethanol & $0 \cdot 08,0 \cdot 13\left(20^{\circ}\right)^{*}$ & ++ \\
\hline Skatole & $0.0025,0.003\left(20^{\circ}\right)^{*}$ & ++ \\
\hline Stilboestrol & $<0.001$ & ++ \\
\hline Terpin hydrate & $0.02\left(20^{\circ}\right)^{*}$ & 0 \\
\hline Toluene & $0.005\left(16^{\circ}\right)^{*}, 0.007\left(25^{\circ}\right) \dagger$ & ++ \\
\hline Tryptophol (2-indolylethanol) & 0.045 & ++ \\
\hline
\end{tabular}

The monomenthyl, monobornyl, or monoisobornyl esters of succinic acid, when dissolved directly in the buffer at a concentration of $c .0 \cdot 15 \%(0.006 \mathrm{M}$; final $\mathrm{pH} 6.5$ ) were fully toxic against all rumen ciliates in $1-2 \mathrm{hr}$. at 35-39 . Menthoxyacetic acid, which like the above acid esters, is readily soluble in the free state in light petroleum, was similarly toxic at a rather higher concentration $(0.015 \mathrm{M})$. 
Action of acidic glucuronides, succinates and menthoxyacetic acid on the ciliates in whole rumen liquor containing bacteria

The compounds mentioned in the last paragraph were again quickly lethal to the ciliates as was also menthol- $\beta$-glucoside, but in the first three instances and the glucoside the smell of the terpene alcohol itself was in evidence within $1 \mathrm{hr}$. This indicates that rapid bacterial hydrolysis of the succinates and also of menthol- $\beta$-glucoside had taken place. The $\beta$-glucuronides of menthol and borneol, however, required at least $24 \mathrm{hr}$. of incubation at $39^{\circ}$ to bring about the same effect. Within $6 \mathrm{hr}$., there was little action on the rumen ciliates and the smell of the terpene alcohol was not perceptible. In all the above instances the presence of viable Streptococcus bovis was demonstrated without difficulty after death of the ciliates. In the experiment with monobornyl succinate, a million-fold dilution of the rumen liquor at the end still contained this bacterium in the viable state.

Inhibitory effect of soluble glucosides and succinates in nutrient agar upon the development of bacteria freshly taken from the rumen. By the technique used, the colony count in the nutrient agar without infusoricidal agent was always of the order of 1000-2000 colonies/plate. The smallest concentrations of infusoricidal agents required to reduce this count by $c .90 \%$ (i.e. to $c$. 100-200 colonies/plate) were as follows: menthol- $\beta$-glucoside, $0.25 \%$, monomenthyl succinate, $0 \cdot 1 \%$, monobornyl succinate, $0 \cdot 4 \%$, monoisobornyl succinate $\mathbf{0 . 4} \%$. Mapharside was so toxic that no colonies of rumen bacteria developed even when the concentration of the arsenical in the nutrient agar was as little as $0.005 \%$.

Antibacterial action of menthol and borneol upon Streptococcus bovis and Sarcina bakeri. In liquid media without ethanol, $67 \%$ saturation with menthol or borneol had no apparent effect on the growth of either organism. 2-Phenylethanol similarly used was, however, bactericidal to both. In media containing $\mathbf{1 . 3} \%(\mathrm{v} / \mathrm{v})$ ethanol, a saturated solution of menthol, but not of borneol, was bactericidal towards Streptococcus bovis. The results with Sarcina bakeri were vitiated by the fact that ethanol itself, at the concentration used, was bactericidal to the organism. As far as could be judged with liquid media containing much less ethanol $(0.33 \%, v / v)$ a saturated solution of borneol had little effect on the growth of this organism. A corresponding aqueous ethanolic solution of menthol was however definitely bactericidal. In general, menthol seemed always to be more bactericidal than borneol.

\section{Density of population and nature of lipase-producing bacteria on rumen contents}

'The highest dilutions of rumen contents from sheep 8060, fed on hay and dried grass, which when incorporated in tributyrin agar definitely gave rise to several colonies with zones of clearing around them, were always $10^{-4}$ and $10^{-5}$. A population of $c$. 500,000 lipase-producing bacteria/g. rumen contents was therefore indicated. The zones although very distinct were always narrow, with only 1-2 mm. between the edge of the colony and the limit of clearing. Nearly 
all the organisms isolated from these colonies proved to belong to the genus Bacillus, and most of the isolates when examined by the procedures of Appleby (1955) proved to be $\boldsymbol{B}$. licheniformis. In fact, several of the strongly proteolytic $B$. licheniformis rumen isolates obtained by Appleby (1955) proved to be lipolytic also when grown anaerobically in tributyrin agar. The lipase of B. licheniformis seemed to be a perfectly stable constituent of this species, still retained after many subcultures on ordinary fat-free media. Other well-known rumen organisms, such as Streptococcus bovis although growing anaerobically on tributyrin agar produced no zones of clearing around the colonies.

\section{DISCUSSION}

Since it is unlikely that the rumen ciliates possess an enzyme capable of hydrolysing the ether link in a stable compound like menthoxyacetic acid (cf. the non-toxicity of phenylmethyl ether to these organisms), it may be supposed that, by analogy, the acid succinates of the terpene alcohols are also toxic in themselves. It is significant that, at an acidic $\mathrm{pH}$ value but not at $\mathrm{pH} 7$, all these acids are readily soluble in light petroleum, and therefore presumably in lipid materials in general, just as the free terpene alcohols are. There is no need to postulate a ciliate esterase in order to account for the toxicity of the monoalkyl succinates, provided it be assumed that the internal contents of the ciliates are definitely acidic in reaction. This may well be so since Heald \& Oxford (1953) and Gutierrez (1955) showed that lactic acid is one of the chief fermentation products, both of glucose and endogenously of storage polysaccharide, by the holotrichs at least. Since rumen bacterial lipase (esterase) undoubtedly exists, these terpene succinates may, in the rumen, be toxic to the ciliates twice over, both before and after hydrolysis, whereas the terpene glucosides have probably only one mode of toxic action, namely after hydrolysis by protozoan or bacterial enzymes.

Incidentally, although indole and skatole are toxic to the ciliates, indoleacetic, -propionic, and -butyric acids unlike menthoxyacetic acid are not (see Eadie \& Oxford, 1954). This may be due to the complete insolubility of these indole derivatives in lipid materials; they are certainly insoluble in light petroleum. The non-toxicity of dulcitol and terpin hydrate may be likewise explained.

One anomaly still remains. Gutierrez (1955) produced good evidence in favour of the view that only Dasytricha among the holotrichs contained a $\beta$-glucosidase enzyme system, whereas we find that menthol- $\beta$-glucoside is indifferently toxic to all three species of rumen holotrichs, even when Isotricha is separated free from Dasytricha, or vice versa. The possibility that washed suspensions of Isotricha contain large numbers of bacteria with a $\beta$-glucosidase enzyme system inside the ciliates, is considered unlikely in view of the failure of Sugden \& Oxford (1952) to demonstrate any such bacteria. The question is being further studied, use being made of more specific staining methods. The inertness of the terpene glucuronides is in agreement with the known absence of a ciliate $\beta$-glucuronidase (Karunairatnam \& Levvy, 1951). It is clear also 
from our results that the rumen bacterial $\beta$-glucuronidase is far less potent than the $\beta$-glucosidase possessed by the same mixed bacterial culture.

We are greatly indebted to the following for gifts of compounds: Drs G. A. Levvy and C. A. Marsh of this Institute for menthol- $\beta$-glucuronide and borneol- $\alpha$-glucoside; Dr P. McCloskey of I.C.I. Ltd., Research Department, 'The Frythe, Welwyn for 7-methoxy-2-methylindole and Dr J. D. Louden, The Chemistry Department, The University, Glasgow, for many other methoxy derivatives of indole. We desire alsc to thank Dr J. C. Appleby for the gift of rumen Bacillus licheniformis isolates.

\section{REFERENCES}

Appleby, J. C. (1955). The isolation and classification of proteolytic bacteria from the rumen of the sheep. J. gen. Microbiol. 12, 526.

Becker, E. R., Schulz, J. A. \& Emmerson, M. A. (1930). Experiments on the physiological relationships between the stomach infusoria of ruminants and their hosts, with a bibliography. Iowa St. Coll. J. Sci. 4, 215.

Beckmann, E. (1909). Versuche zur Spaltung der racemischen Camphersäuen und der Isoborneole in die aktiven Komponenten. Ber. dtsch. chem. Ges. $42,485$.

Conchie, J. (1954). $\beta$-Glucosidase from rumen liquor. Preparation, assay and kinetics of action. Biochem. J. 58, 552.

Dogiel, V. A. (1927). Monographie der Familie Ophryoscolecidae. Arch. Protistenk. $59,1$.

Eadie, J. M. \& Oxfond, A. E. (1954). A remarkable disintegrative effect of skatole upon certain rumen ciliate protozoa. Nature, Lond. 174, 973.

EADIE, J. M. \& OXFord, A. E. (1955). Factors involved in the production of a novel kind of derangement of storage mechanism in living holotrich ciliate protozoa from sheep rumen. J. gen. Microbiol. 12, 298.

EhrLICH, F. (1912). Über Tryptophol ( $\beta$-Indolyl-aethylalkohol), ein neues Gärprodukt der Hefe aus Aminosäuren. Ber. dtsch chem. Ges. 45, 883.

Eisenberg, G. M. (1939). A Nile blue culture medium for lipolytic micro-organisms. Stain Tech. 14, 63.

Ferguson, J. (1939). Use of chemical potentials as indices of toxicity. Proc. Roy. Soc. B, 127, 387.

Fischer, E. \& Raske, K. (1909). Synthese einiger Glucoside. Ber. dtsch. chem. Ges. $42,1465$.

Gutierrez, J. (1955). Experiments on the culture and physiology of holotrichs from the bovine rumen. Biochem. J. 60, 516.

Handbook of Chemistry and Physics (1947). 30th ed. Cleveland: Chemical Rubber Publishing Co.

Heald, P. J. \& Oxford, A. E. (1953). Fermentation of soluble sugars by anaerobic holotrich ciliate protozoa of the genera Isotricha and Dasytricha. Biochem. J. $53,506$.

Huhtanen, C. N., Rogers, M. R. \& Gall, L. S. (1952). Improved techniques for isolating and purifying rumen organisms. J. Bact. 64, 17 .

Hungate, R. E. (1955). In Biochemistry and Physiology of Protozoa (Vol. iI, ed. by Hutner, S. H. \& Lwoff, A.), pp. 159-179. New York: Academic Press Inc.

Karunairatnam, M. C. \& Levvy, G. A. (1951). A glucuronide-decomposing enzyme from rumen micro-organisms. Biochem. J. 49, 210.

Krages, A. \& AllendorfF, P. (1898). Über die Reduction aromatischen Ketone durch Natrium und Alkohol. Ber. dtsch. chem. Ges. 31, 998.

LEETE, E. \& Marion, L. (1953). The hydrogenolysis of 3-hydroxymethylindole and other indole derivatives with lithium aluminium hydride. Canad. J. Chem. 31, 775 . 
McNaught, M. L., Owen, E. C., Henry, K. M. \& Kon, S. K. (1954). The utilization of non-protein nitrogen in the bovine rumen. 8 . The nutritive value of the proteins of preparations of dried rumen bacteria, rumen protozoa and brewer's yeast for rats. Biochem. J. 56, 151.

MacPherson, M. J. (1953). Isolation and identification of amylolytic streptococi from the rumen of the sheep. J. Path. Bact. 66, 95.

MANN, S. O., MAsson, F. M. \& OXFord, A. E. (1954). Facultative anaerobic bacteria from the sheep's rumen. J. gen. Microbiol. 10, 142.

Organic Syntheses (1955). Collective Vol. 3, p. 544. New York: John Wiley and Sons. Inc.

Potts, K. T. \& Saxton, J. F. (1954). Methylation of indoles. J. Chem. Soc. p. 2641.

Quick, A. J. (1927). The preparation of borneol glycuronic acid and glycuronic acid. J. biol. Chem. 74, 331.

SiJPesteisn, A. K. \& Elsden, S. R. (1952). The metabolism of succinic acid in the rumen of the sheep. Biochem. J. 52, 41 .

Sugden, B. \& Oxford, A. E. (1952). Some cultural studies with holotrich ciliate protozoa of the sheep's rumen. J. gen. Microbiol. 7, 145.

Weissberger, A. \& Proskauer, E. S. (1955). Organic Solvents, 2nd ed. New York: Interscience Publ. Inc.

Williams, R. T. (1947). Detoxication Mechanisms. London: Chapman and Hall Ltd.

(Received 2 August 1955) 